\title{
Impact of Performance-Based Financing (PBF) and On Maternal and Child Health in Adamawa State
}

\author{
Yakubu Suleiman, Ujiro Igbudu \& Julia Adesua \\ Department of Health, Safety and Environmental Education, Faculty of Education, University of Benin City, Nigeria.
}

Copyright: $\odot 2021$ Yakubu Suleiman et al. This is an open access article distributed under the terms of the Creative Commons Attribution License, which permits unrestricted use, distribution, and reproduction in any medium, provided the original author and source are credited.

The purpose of this study is to investigate the impact of performance-based financing $(P B F)$ on maternal and child health in Nigeria. PBF is proposed as a holistic reform approach that aims to improve the aforementioned shortcomings among others in healthcare provision. In Nigeria, this unique funding approach based on performance was piloted in 2011 with Adamawa, Nasarawa and ONDO states and later additional five States are Borno, Yobe, Gombe, Taraba and Bauchi which were added in 2016. It is expected that if these States demonstrates effectiveness in yielding the expected health outcomes especially as it pertains to the attainment of the stated health-related SDGs, the project would be implemented in all the States of the federation. This necessitates the need for an objective assessment of the impact of Performance-Based Financing especially as it pertains to maternal and child health. Against this background, data on key health indicators like number of ANC visits, Completely Vaccinated Children (CVC), Out Patient Department (OPD) attendance, Deliveries at the health centre and the number of Family Planning Services Uptake were collected at the Primary health care centre level in three States-Adamawa, Nassarawa and ONDO States. The Ex post facto and causal research design was used for the study. A sample size of one hundred and sixty two (162) primary health care facilities will be selected for the study representing approximately $20 \%$ of the study population which is adequate. This selection was done using a multi-stage sampling technique. Data collected was analyzed using basic descriptive statistics and the General Linear Model (GLM) approach involving the Two-way Mixed effects ANOVA Statistic. It was found that at 0.05 significant levels PBF health facilities perform better than the conventionally funded health facilities in terms of number of ANC visits, OPD attendance, deliveries at the health centres, CVCs and the number of family planning services. Consequently, it was concluded that PBF has had a significant impact on the health care quality of Primary Health Care Centres in the Piloted States. As a result it is recommended that the PBF program should be scaled up to all the States of the Federation and also the need to incorporate the PBF tenets in to the new Basic Health Care Provision Funds, BHCPF, among others were recommended.

Keywords: PBF, Health, ANC, Maternal.

\section{Background}

Performance-Based Financing (PBF) is now increasingly being adopted as a way of driving efficiency in developing countries' Primary Health Care Delivery System. Performance-Based Financing (PBF) is a form of funding for project implementation or service provision, where the principal, who provides the funding, pays the agent, who implements the project or provides the service, upon achieving predefined results (Grittner, 2013). In Africa alone, more than 35 countries, including Nigeria, are implementing or are in the process of introducing payment methods that reward performance (Bonfrer, Soeters, Van de Poel, Basenya, Longin, \& Van de Looij, 2013). Performance-Based Financing is part of result-based financing programme in which financial incentives are provided to the health centres (providers of health services) upon the meeting up of initially stated objectives. In this, the health care providers are given autonomy to creatively meet stated objectives and get the financial bonus with the State primary health care agencies (the agent) as playing the regulatory role. PBF utilizes the phrase "applies market forces but seeks to correct market failures to attain health gains" (African PBF Community of Practice Discussion Group, 2010).

Performance-Based Financing programme has been on pilot testing in Nigeria since 2011. In the first year, precisely on December 2011, the programme was piloted in three States - Adamawa, Ondo and Nasarawa States. Even in these selected States, only one local government area was selected from each of the selected States. 
Currently, the PBF programme has been scaled up to cover more areas in the initial States and some other States were selected such as Borno, Yobe, Gombe, Taraba and Bauchi States (Adamawa State Ministry of Health, 2018).

The use of the result-based approach in funding programmes is not a new one. It can be said to be an off-shoot of international efforts to make developmental investments more effective in achieving the intended goals (Grittner, 2013). It is believed that by linking funding to be more closely attached to results, positive outcomes are expected in no distant future. The goal to improve the effectiveness and efficiency of development aid is not a recent phenomenon. Probably the most important declaration was the Paris Declaration on Aid Effectiveness in 2005, which set out five principles that donors, recipient countries and multilateral had agreed upon to improve the effectiveness of aid. These aid-effectiveness principles are ownership; alignment of donor support with partner country strategies; harmonization of donor actions; mutual accountability of donors and partners; and results-based management. These and similar efforts that focus on results-based management in the quest donated fund accountability and efficiency provided the bedrock for Performance-Based Financing.

Performance-Based Financing (PBF) is anchored on a powerful assumption that individuals and organizations are motivated to perform better by incentives. PBF can be said to be under the umbrella of Result Based Financing $(\mathrm{RBF})$. Generally, RBF is defined as any programme in which the principal sets financial or other incentives for an agent to deliver predefined outputs or outcomes and rewards the achievement of these results upon verification (Musgrove, 2010). Two types of RBF can be distinguished - PBF and Conditional Cash Transfer (CCT) (Grittner, 2013). Performance-Based Financing (PBF) targets the supply side, whereas CCTs target the demand side of a given market. The supply side involves service providers and service delivery.

In the health care sector, Performance-Based Financing implementation aims at setting incentives for health workers who are the service providers to deliver a good performance. Indicators are set by the principal - often together with the agent. Payment takes place against the achievement of these predefined indicators.

In Nigeria, the implementing agents are the National Primary Health Care Development Agency (NPHCDA), the State Primary Health Care Development Agencies and the Federal Ministry of Health (Adamawa State Ministry of Health, 2018). On the other hand, the principal is the donor, the World Bank.

The agent at the state level which is the State Ministry of Health (SMOH) utilizes a 'contract in' approach where they serve as the regulator over the providers. The providers are institution contracted to supply services (Federal Ministry of Health, FMOH, 2013). Clarified the providers to include health centres and general hospitals, public, quasi-public and private health facilities. Autonomy is provided to the health centres (the providers) to overcome bottlenecks that impeded fund from getting to them for direct impact on the public and to improve grassroots ownership of the programme for sustainability. According to Witter, Toonen, Meessen, Kagubare, Fritsche and Vaughan (2013), providers are assumed to have or must be given and supported in using, the autonomy to be able to respond in a creative way to overcome bottlenecks in attaining results at their level.

Although the programme has an in-built evaluation research system with funds dedicated to it, little empirical works have been published on this subject in Nigeria. Besides, since the evaluation is an in-built with the 
investigators as beneficiaries of the programme, the candidness in reporting every aspect of the evaluation results may be questionable. This presents the need for an independent empirical investigation.

\section{Research Questions}

The following research questions were raised to guide the study:

(1) Does PBF health facilities perform better than conventionally funded health facilities in terms of Ante Natal Care (ANC) attendance?

(2) Does PBF health facilities perform better than No Financial Intervention (NFI) health facilities in terms of number of Children Vaccinated Completely (CVC)?

(3) Does PBF health facilities perform better than No Financial Intervention (NFI) health facilities in terms of number of deliveries at the health facilities?

(4) Does PBF health facilities perform better than No Financial Intervention (NFI) health facilities in terms of number of Out Patient Department (OPD) attendance?

(5) Does PBF health facilities perform better than No Financial Intervention (NFI) health facilities in terms of number of family planning services uptake?

\section{Method}

The Ex post facto and causal research design was used for the study. This involves the use of already made data or pre-existing groups without randomization. The group that received the intervention is termed the experimental group while the group that did not receive the intervention is termed the control group.

In the context of this study, the health facilities that adopted Performance-Based Financing or Decentralized Facility Financing will be termed experimental groups while those that did not adopt Performance-Based Financing formed the control group. The population of the study consists of all functional Primary Health Care facilities of Performance-Based Financing (PBF) and Non-Financial Intervention Health facilities in the implementing Local Government in Adamawa, Nasarawa and Ondo states.

A sample size of two hundred and sixteen (162) primary health care facilities were selected for the study representing approximately $20 \%$ of the study population which is adequate. This selection was done using a multi-stage sampling technique. Data were collected using a pro forma by the researcher with the aid of three (3) research Assistants. These three (3) researches assistants will be drawn from experienced PBF verifiers. In addition to their experience, they will be subjected to two days of training on the procedures to ensure that data are collected according to specified procedures. Data collected was sorted, coded and analyzed using basic descriptive statistics and General Linear Model (GLM) involving Two-way Mixed effect Annova Statistics.

\section{Results}

Research Question one: Does PBF health facilities perform better than conventionally funded health facilities in terms of Ante Natal Care (ANC) attendance. 
Table 1. Descriptive statistics showing the frequency, mean and standard deviation for PBF health facilities and No-Financial-Intervention (NFI) Health Facilities

\begin{tabular}{|c|c|c|c|c|}
\hline \multicolumn{4}{|c}{} & \multicolumn{5}{c|}{ Descriptive Statistics } \\
\hline \multirow{4}{*}{ ANC_2017 } & Tx & Mean & SD & N \\
\cline { 2 - 5 } & NFF & 32.52 & 65.533 & 95 \\
\cline { 2 - 5 } & PBF & 410.64 & 1031.305 & 67 \\
\cline { 2 - 5 } & Total & 188.90 & 688.045 & 162 \\
\hline \multirow{3}{*}{ ANC_2018 } & NFF & 34.76 & 103.401 & 95 \\
\cline { 2 - 5 } & PBF & 308.27 & 733.083 & 67 \\
\cline { 2 - 5 } & Total & 147.88 & 494.776 & 162 \\
\hline \multirow{3}{*}{ ANC_2019 } & NFF & 47.57 & 146.610 & 95 \\
\cline { 2 - 6 } & PBF & 232.61 & 493.550 & 67 \\
\cline { 2 - 6 } & Total & 124.10 & 347.510 & 162 \\
\hline \multirow{3}{*}{ ANC_2020 } & NFF & 17.71 & 45.648 & 65 \\
\cline { 2 - 6 } & PBF & 214.96 & 347.892 & $\mathbf{1 6 2}$ \\
\cline { 2 - 6 } & Total & $\mathbf{9 9 . 2 8}$ & $\mathbf{2 4 5 . 6 1 3}$ & 67 \\
\hline
\end{tabular}

From the descriptive statistics it is evident that PBF health facilities has a higher mean ANC visits $(\mathrm{N}=67$, $\mathrm{M}=291.62$ ) more than the Non-Financial-Intervention (NFI) facilities ( $\mathrm{N}=162, \mathrm{M}=33.14$ ).

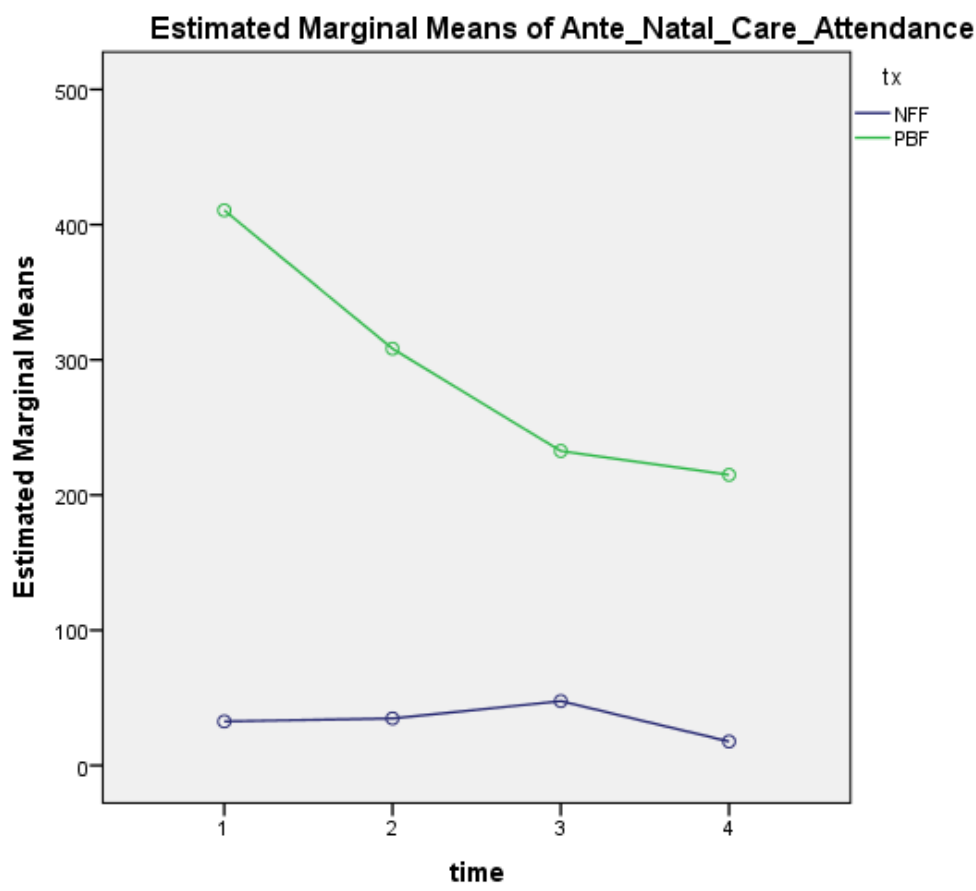

Fig.1. Line graph comparing the Estimated Marginal Means of PBF and NFI from 2017 to 2020 
From fig.1, it is clear that from 2017 to 2020 PBF has had a higher mean ANC attendance over the conventionally funded health facilities, NFI. It worthy to note that from 2017, PBF health facilities across the states have been experiencing a decline in ANC attendance. In spite of this huge decline, the PBF funded health facilities still have a higher mean ANC attendance over the conventionally funded health facilities.

Table 2. Descriptive statistics showing the frequency, mean and standard deviation for PBF health facilities and No-Financial-Intervention (NFI) Health Facilities CVCs 2017 to 2020

\begin{tabular}{|c|c|c|c|c|}
\hline & tx_CVC & Mean & Std. Deviation & N \\
\hline \multirow{3}{*}{ CVC_2017 } & NFF & 40.37 & 94.380 & 90 \\
\cline { 2 - 5 } & PBF & 431.51 & 493.565 & 72 \\
\cline { 2 - 5 } & Total & 214.21 & 387.769 & 162 \\
\hline \multirow{3}{*}{ CVC_2018 } & NFF & 37.46 & 85.332 & 90 \\
\cline { 2 - 5 } & PBF & 310.40 & 410.629 & 72 \\
\hline \multirow{3}{*}{ CVC_2019 } & Total & 158.77 & 311.277 & 162 \\
\cline { 2 - 5 } & NFF & 45.74 & 71.259 & 90 \\
\cline { 2 - 5 } & PBF & 288.67 & 404.929 & 72 \\
\hline \multirow{3}{*}{ CVC_2020 } & Total & 153.71 & 299.628 & 162 \\
\cline { 2 - 5 } & NFF & 66.82 & 98.027 & 72 \\
\cline { 2 - 5 } & PBF & 271.36 & 348.093 & 162 \\
\hline
\end{tabular}

From the descriptive statistics it is evident that PBF health facilities has a higher average monthly mean CVCs of $\mathrm{PBF}(\mathrm{M}=325.49)$ is more than that of the Non-Financial-Intervention (NFI) facilities ( $\mathrm{M}=47.60)$.

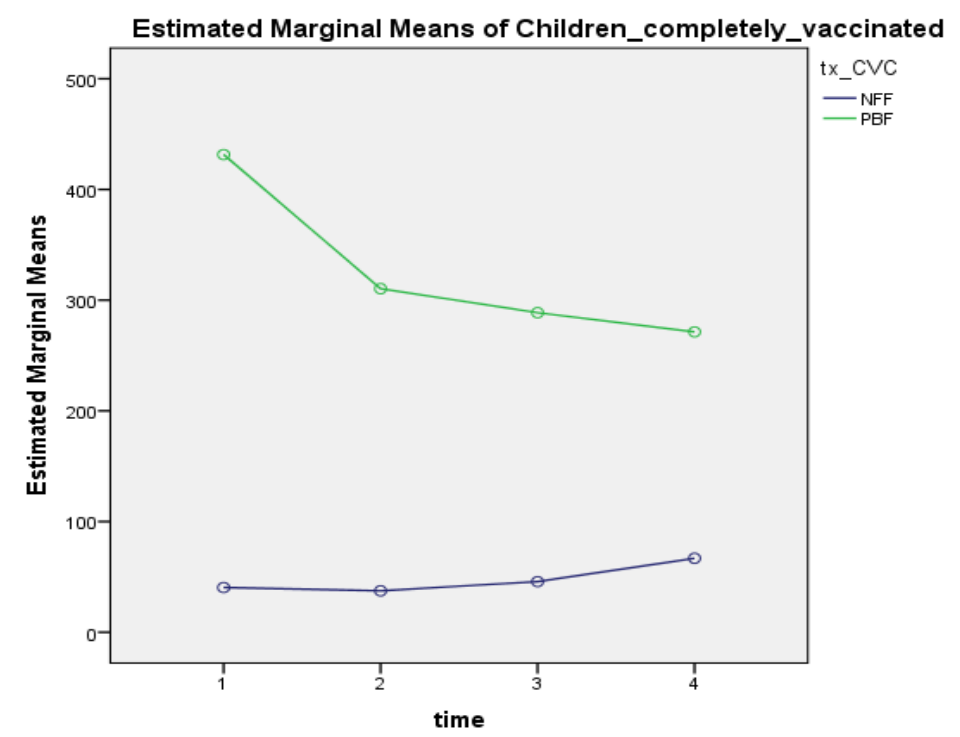

Fig.2. Line graph comparing the Estimated Marginal Means of number of completely vaccinated for PBF health centres and NFI health centres from 2017 to 2020 
From fig.2, it is clear that from 2017 to 2020 PBF have had a higher mean number of completely vaccinated children over the conventionally funded health facilities, NFI. It worthy to note that from 2017, PBF health facilities across the states have been experiencing a decline in number of completely vaccinated children. This could probably be attributed to a defect in implementation or funding issues. While on the other hand the conventionally funded health facilities have been from 2017 having a low yet steady increase in number of completely vaccinated children. In spite of this huge decline, the PBF funded health facilities still have a higher mean ANC attendance over the conventionally funded health facilities.

Table 3. Descriptive statistics showing the frequency, mean and standard deviation for PBF health facilities and No-Financial-Intervention (NFI) Health Facilities CVCs 2017 to 2020

\begin{tabular}{|c|c|c|c|c|}
\hline & tx_Deliveries & Mean & Std. Deviation & $\mathbf{N}$ \\
\hline \multirow{3}{*}{ Deliveries_2017 } & NFF & 11.86 & 37.511 & 90 \\
\hline & PBF & 527.17 & 960.964 & 72 \\
\hline & Total & 240.88 & 688.468 & 162 \\
\hline \multirow{3}{*}{ Deliveries_2018 } & NFF & 7.09 & 19.609 & 90 \\
\hline & PBF & 379.67 & 692.596 & 72 \\
\hline & Total & 172.68 & 496.226 & 162 \\
\hline \multirow{3}{*}{ Deliveries_2019 } & NFF & 8.63 & 21.582 & 90 \\
\hline & PBF & 285.39 & 443.602 & 72 \\
\hline & Total & 131.64 & 325.679 & 162 \\
\hline \multirow{3}{*}{ Deliveries_2020 } & NFF & 7.98 & 21.108 & 90 \\
\hline & PBF & 190.56 & 197.044 & 72 \\
\hline & Total & 89.12 & 160.157 & 162 \\
\hline
\end{tabular}

From the descriptive statistics it is evident that PBF health facilities has a higher average monthly mean number of deliveries in PBF health facilities (M=345.7) is more than that of the Non-Financial-Intervention (NFI) facilities $(\mathrm{M}=35.56)$.

\section{Conclusion}

Based on the findings of this study it can be deductively concluded that the PBF intervention programme is good enough to not only continue in the pilot States but also good enough to be scaled up to the entire States of the Federation. This is because it has been found to improve the health care facilities' performance on the five key health care indicators considered in this study - number of ANC, CVC, OPD, Deliveries, and Family planning 
services uptake more than the conventional financing approach. Intuitively one can also conclude that more likely the programme must have improved other key health indicators that were not captured in the study.

\section{Recommendations}

Based on the findings and the subsequent conclusion drawn, the following are recommended:

(1) The Federal Ministry of Health and the Ministry of Finance should work to ensure that the PBF program is scaled up to all States of the Federation.

(2) The PBF program is a capital intensive one, so implementing it the way it has been pilot tested by the World Bank may not be feasible without external funding. Therefore it is recommended that the basic tenet of it which is the performance-based financing should be adopted based on available fund by the Federal Government in all its health facilities funding models across the States of the federation.

(3) In line with the second recommendation, the new Basic Health Care Provision Funds, BHCPF, should be disbursed, monitored and evaluated using the Result-Based Financing Model of PBF program.

\section{Declarations}

\section{Source of Funding}

This research did not receive any grant from funding agencies in the public, commercial, or not-for-profit sectors.

\section{Competing Interests Statement}

The authors declare no competing financial, professional and personal interests.

\section{Consent for publication}

Authors declare that they consented for the publication of this research work.

\section{Reference}

Grittner, A.M. (2013). Results-based Financing: Evidence from performance-based financing in the health sector. Germany: DeutshesInstitut Fur Entwicklungspolitik (D.I.E) \& German Development Institute.

Bonfrer, I., Soeters, R., Van de Poel, E., Basenya, O., Longin, G. \& Van de Looij F. (2013). The effects of performance-based financing on the use and quality of health care in Burundi: an impact evaluation. Lancet. 381. Adamawa State Ministry of Health, 2018.

Musgrove, P. (2011). Rewards for good performance or results: a short glossary. In. Washington, D.C.: The World Bank.

Toonen J. C.A., Vergeer, P. \&Elovainio, R. (2009). Learning lessons on implementing performance based financing from a multi-country evaluation. In: KIT Royal Tropical Institue, in collaboration with Cordaid and World Health Organization. 